\title{
Forgotten Roles of Health Services Provision in Poor Tanzania: Case of Faith Based Organizations' Health Care Facilities in Dodoma Region
}

\author{
Mshana Zainabu M. ${ }^{1,}$, Zilihona Innocent E. ${ }^{2}$, Canute Hyandye B. ${ }^{2}$ \\ ${ }^{1}$ Paradigms Institute, Kimara, Dar es Salaam, Tanzania \\ ${ }^{2}$ Institute of Rural Development Planning (IRDP), Dodoma, Tanzania
}

Email address:

mussa.zainabu@yahoo.com (Mshana Z. M.)

\section{To cite this article:}

Mshana Zainabu M., Zilihona Innocent E., Canute Hyandye B.. Forgotten Roles of Health Services Provision in Poor Tanzania: Case of Faith Based Organizations' Health Care Facilities in Dodoma Region. Science Journal of Public Health. Vol. 3, No. 2, 2015 , pp. $210-215$. doi: $10.11648 /$ j.sjph.20150302.18

\begin{abstract}
Health services are vital for economic growth in Tanzania however; its provision is considered as forgotten role. This paper analyzed the problem of health services provision and the factors affecting its provision in poor Tanzania. The study was limited to Faith Based Organization's (FBO's) health care facilities of Dodoma region in Tanzania. A cross sectional research design and cluster sampling technique followed by simple random sampling technique was used during the study. Questionnaire survey, interview and participants observation methods were adopted to collect primary data from 394 respondents. Binary logistic regression model was used to determine the main factors affecting health services provision in FBO's health care facilities of Dodoma region. Findings of this study revealed that health services provision in poor Tanzania are the roles that have been forgotten due to various problems existing in FBO's health care facilities. These are; high costs of drugs, long distance from home to health care facilities, insufficient numbers of doctors and nurses, lack of medicine and long waiting time for treatment. The main factors leading to these problems were the presence of low budget in health sector, poor working environment, poor infrastructure, high running cost and business orientation notion. It is recommended that FBO's should increase the budget in health sector as well as cooperating with the government to facilitate infrastructure and human resource improvement and maintenance.
\end{abstract}

Keywords: Health Services Provision, Forgotten Roles, Poor, Faith-Based Organizations, Tanzania

\section{Introduction}

Auguste Comte, a French philosopher in 1851 proposed the idea of altruism. Under this idea, everyone is considered to think about others and care for them just as they care for themselves. The model has been used within families, close friends and religious communities [1]. The ideas of altruism made the initial point for Faith Based Organizations (FBOs) to utilize time and resources for the betterment of the society. Faith Based Organizations have been at a forefront in providing vital services to the poor particularly in health. They are found even in most inaccessible areas where government services do not reach and sometimes poorly served by the state [2]. Faith Based Organizations probably provide the best social and physical infrastructure in the poorest communities because Churches, Temples, Mosques and other places of worship are the focal points for the communities they serve [3]. According to the Department for International Development (DFID) [4], FBOs provide $50 \%$ of health services in sub-Saharan Africa. For example, they offer $43 \%$ of medical work in Tanzania, $40 \%$ in Malawi, 34\% in Ghana and 9\% in Congo (DRC).

In addition, health services provision in FBO's health care facilities are commonly observed to have resources, personnel, technical expertise and community links to health action and are normally delivered by committed practitioners with high level of client satisfaction. Personnel working in FBO's health care facilities are found to be motivated to serve the poor by working experience and by social justice value $[5,6]$. The common focus of their services in primary health care facilities together with an orientation towards disadvantaged communities reflects equity values [7].

These value and roles of FBO's are very potential in health services provision to the poor countries like Tanzania. 
However, the growing evidence showed that health services provision in the country is unwillingly and considered as forgotten. Data to indicate the problems and reasons for problems of health services provision in Tanzania regardless of the efforts of FBO's to provide health services to the poor are missing. Hence, the study to show how the role of health services provision in Tanzania has been forgotten was done in Dodoma region specifically; it analyzed the problems of health services provision and factors that affect health services provision in FBO's health care facilities of Dodoma urban and Kondoa districts.

\section{Methodology}

\subsection{Description of the Study Area}

The study was carried out in Dodoma region, specifically in Dodoma urban and Kondoa districts, Tanzania. Dodoma is one of the 30 regions in Tanzania. It is almost centrally located on the Tanzania Mainland laying between $5^{0} 30^{\prime}$ and $7^{0}$ latitude and 360 longitude line. The region is administratively divided into seven districts; these are Dodoma urban, Bahi, Chamwino,Kondoa, Mpwapwa, Chemba and Kongwa[8].

The region covers an area of 41,310 $\mathrm{km}^{2}$ with 2,083,588 inhabitants characterized by Bantu speaking people who form $75 \%$ of the regional population. These include the Gogo, Rangi, Nguu, Zigua, Kaguru, and Sagara. The Nilotics or Nilo Hamites form another group, which include the Masai, Fyomi, Mang'ati, Mbulu and Tatoga.Apart from these, the region comprises other ethnic groups from all over the world including the Indians, Arabs and Somalis who are mainly found in urban centers and rural trading centers.

Health services provision in the region is still unfavorable whereby high maternal mortality rate, high under five mortality rates and high prevalence rate of HIV/AIDS, unavailability of qualified personnel, harassment from doctors and nurses, high costs for drugs, lack of enough drugs and long waiting time for treatments are the primary health problems in the region. Apart from that in average, a person needs to walk for about two to ten kilometers in order to get services like health, school, water, market and the like. Thus, accessibility to basic social services is still a problem to the people in the region [8].

\subsection{Research Methods}

A cross-sectional research design was used during data collection. The cluster sampling followed by the simple random sampling technique was used in the study. Questionnaire survey, interview and participant observation methods were adopted as tools for data collection in the field. Based on the population of the two districts, sample size was 394 respondents (169 from Dodoma urban district and 225 from Kondoa district). The sample was calculated using the formula in equation (1) (Kothari, 2005).

$$
\mathrm{n}=\left(\mathrm{Z}^{2} \mathrm{pq}\right) / \mathrm{d}^{2}
$$

Where:

$\mathrm{n}=$ Sample size when population is greater than 10,000

$\mathrm{Z}=$ Standard normal deviate, set at $1.96(\approx 2.0)$ corresponding to $95 \%$ confidence level,

$\mathrm{p}=$ Proportion in the target population estimate; if not known use $50 \%$.

$\mathrm{d}=$ Degree of accuracy desired, set at .05 or .02 .

$\mathrm{q}=1.0-\mathrm{P}$

Data analysis in this study was based on the inferential statistic analysis whereby, binary logistic regression models was developed to determine the main factors affecting health services provision in FBOs health care facilities. The models represent the probability of an event to occur whereas the probability of the event not to occur is given as pro (no event) $=1$-pro (event). The formula used is shown in equation (2)as quoted from Kothari (2005).

$$
\mathrm{Yi}=1 / 1+\mathrm{e}^{\mathrm{zj}}
$$

Where:

$\mathrm{Yi}=$ dependent variable depicting health services delivery in FBOs health care centers.

$\mathrm{zj}=$ the combination of influencing factors (independent variables) i.e. $\beta 0 \mathrm{j}+\beta \mathrm{j} 1 \mathrm{Xj} 1+\beta \mathrm{j} 2 \mathrm{Xj} 2+\ldots \ldots \beta \mathrm{j} \mathrm{pXj}$.

$\beta 0=$ Constant term of the model without the independent variables

$\beta=$ independent variable coefficient showing the marginal effects (positive or negative) of the unit change in the independent variables on dependent variable.

$\mathrm{e}=$ is the base of natural logarithm, approximately exp $=$ 2.71828 .

$\mathrm{p}=$ total number of independent variables.

$\mathrm{X} 1$ to $\mathrm{Xp}=$ independent variables.

Binary logistic regression which is a binary technique for estimating the probability of an event to occur was adopted because of the dichotomous nature of dependent variable and nominal and numerical nature of independent variables [9].

\section{Results and Discussion}

\subsection{Problems of Health Services Provision(HSP) in FBOs Health Care Facilities}

Results presented in this paper denotes that HSP in FBO's health care facilities of Dodoma urban and Kondoa districts is not that much better as highlighted by other literatures shown in the introduction section. FBO's have been at a forefront in providing vital services to the poor particularly in health, they reach the poor people even risk and inaccessible areas[2].They also provide services to all with justice[5,6]. High costs for drugs, long distances to health care facilities and lack of personnel have been pointed out by respondents as problems experienced at FBO's health care facilities of Dodoma urban and Kondoa districts as indicated in Fig.1.

Although results in Fig.1 shows that 50.1\% (399) of respondents under multiple responses failed to suggest different problems existing in FBO's health care facilities, $22.6 \%$ (172) of respondents pointed out that, the serious problem in FBO's health care facilities was high costs for 
drugs. Another problem was long distances from home to health care facilities as indicated by $14.1 \%$ (112) respondents. This is a result of having very few health care facilities operated by FBO's in the two districts [10]. Dodoma urban have a total of nine FBO's health care facilities while Kondoa has only one health care facility.

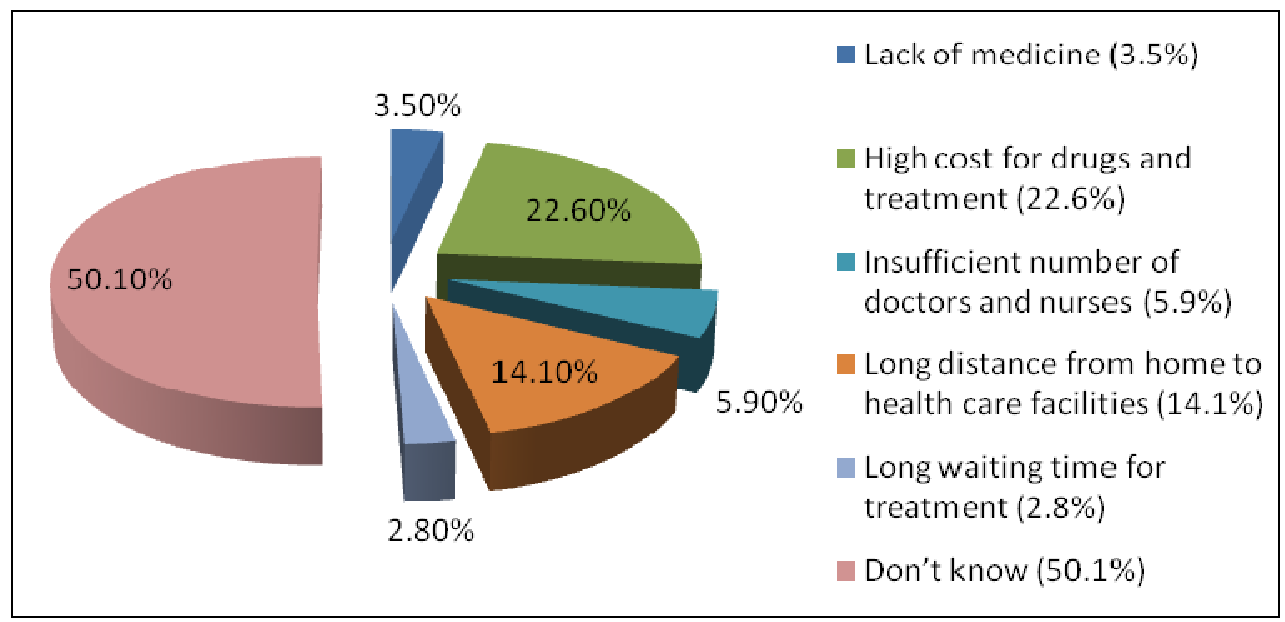

Figure 1. HSP problems in FBO's health care facilities of Dodoma and Kondoa districts (Source: Fieldwork Survey, 2012).

Other problems pointed out by respondents were insufficient number of doctors and nurses by $39(5.9 \%)$ respondents, lack of medicines by $28(3.5 \%)$ respondents and long waiting time for treatment by $20(2.8 \%)$ of respondents. These results are also in agreements with other previous studies $[12,13]$ which pointed out unavailability of drugs, discrimination and long distance, lack of transport, and indirect costs as well as corruption to be among the problems hindering the poor from attaining health services.

Results in Fig. 1 are also contrary with findings of other authors [5, 6] on the personnel capacity and level of satisfaction on FBO's heath care facilities. They argue that health services provision in FBO's health care facilities are commonly observed to have resources, personnel, technical expertise and community links to health action and are normally delivered by committed practitioners with high level of client satisfaction. In addition, personnel working in FBO's health care facilities are found to be motivated to serve the poor by working experience and by social justice value $[5,6]$.

\subsection{Causes of HSP Problems in FBO's Health Care Facilities of Dodoma Urban and Kondoa Districts}

The problems indicated in Fig. 1 have been caused by a number of reasons. These reasons are shown in Table 1 in terms of percentages.

High running costs $(14 \%)$ and poor infrastructures $(12.4 \%)$ have featured out in Table 1 as the leading causatives of the problems pointed by respondents. Insufficient budget in health sector $(5.2 \%)$ have forced the FBO's health care facilities to turn from being providing vital services to the poor based on generosity and compassion to pure business firms oriented [3].

The results in Table 1 are supported by findings of other authors $[14,13]$ that identified the similar reasons for problems in health care facilities in Tanzania. Hence, the presence of high running costs, poor infrastructure, poor ethical conduct for workers, uncomfortable working environment, poor health education and business in health services affect health services provisions in FBO's health care facilities of Dodoma urban and Kondoa districts.

Table 1. Reasons for HSP problems in FBOs health care facilities

\begin{tabular}{ll}
\hline Reason & Percentage \\
\hline Running costs & 14 \\
Poor health education to the patients & 5.6 \\
Poor infrastructure & 12.4 \\
High population growth Vs health facilities available & 10.5 \\
Inadequate income to the people & 8.2 \\
Lack of work ethics & 11.9 \\
Insufficient budget & 5.2 \\
Uncomfortable working environment & 3.8 \\
Business oriented & 4.8 \\
Don't know & 7.9 \\
Nil & 15.6 \\
\hline
\end{tabular}

Source: Fieldwork Survey, 2012

\subsection{Binary Logistic Regression Analysis of the Causes of Health Services Provision Problems in Dodoma Urban and Kondoa Districts}

Results in Table 1(reasons for problems of HSP in FBO's health care facilities) were analyzed using binary logistic regression model to identify the mostly reasons likely to affect health services provision in FBO's health care facilities. These reasons were used as independent variables in the analysis as it is indicated in Table 2 . 
Table 2. Reasons for health services provisions problems in FBO's health care facilities.

\begin{tabular}{|c|c|c|c|c|c|c|}
\hline Variables & $\boldsymbol{\beta}$ & S.E & Wald & df & Sig & $\operatorname{Exp}(\beta)$ \\
\hline Running costs & -.654 & .119 & 30.122 & 1 & $.000 *$ & .520 \\
\hline Health education to the patient & .144 & .112 & 1.661 & 1 & $.197 \mathrm{~ns}$ & 1.155 \\
\hline Infrastructure & -.159 & .120 & 1.765 & 1 & $.184 \mathrm{~ns}$ & .853 \\
\hline Health facilities & -.203 & .109 & 3.454 & 1 & $.063 \mathrm{~ns}$ & .816 \\
\hline Income of the society & -.042 & .131 & .105 & 1 & $.745 \mathrm{~ns}$ & .959 \\
\hline Ethical conduct for workers & -.101 & .112 & .810 & 1 & $.368 \mathrm{~ns}$ & .904 \\
\hline Budget in the health sector & -.022 & .139 & .025 & 1 & $.874 \mathrm{~ns}$ & .978 \\
\hline Business oriented & .286 & .098 & 8.590 & 1 & $.003 *$ & 1.331 \\
\hline Constant & 2.488 & .929 & 7.167 & 1 & $.007 *$ & 12.040 \\
\hline
\end{tabular}

Source: Fieldwork survey, 2012

Note:

The model $-2 \log$ Likelihood $=378.130$; model chi-square $=88.046$ at $\mathrm{p}<0.05$; overall percentage $=71.9 \%$; number of cases $=342$; Nagelkerke R-square $=$ $0.305 ; \beta=$ regression coefficient; $\mathrm{SE}=$ standard error of the estimate; Wald $=$ Wald statistics depicting relationship between dependent and independent variables; $\mathrm{df}=$ degree of freedom; $\operatorname{Exp}(\beta)=$ odds ratio (probability of even to occur over probability of not occurring); Sig $=$ significance level or $\mathrm{p}$ values; $*=$ statistically significant at $\mathrm{p}<0.05$ level and $\mathrm{ns}=$ non-significant at $\mathrm{p}>0.05$ level of significance.

The logistic regression model in Table 2fits well to the data due to significance value $(\mathrm{p}<0.007)$ of the constant. The -2 log likelihood of 378.130 implies good fitness of data to the model, whereas the overall percentage of $71.9 \%$ signifies correct predictions of independent variables by the model. The model chi-square of 88.046 at 9 degree of freedom and $p<0.05$ implies a significant influence of the independent variables on the dependent variable. Coefficient of determination $\left(\mathrm{R}^{2}\right)$ obtained (0.305) indicates that, the mentioned independent variables in Table 2 accounted for $31 \%$ of the variation in the dependent variable. Hence, the listed independent variables determine the dependent variable (health services provision in FBO's health care facilities) by $31 \%$. The remaining $69 \%$ is determined by other factors not identified in this study.

The Wald statistics determine whether particular independent variables have significant effects on the dependent variable. In this regard, two factors were significantly likely to affect health services provision in FBO's health care facilities in Dodoma urban and Kondoa districts. These are running costs with $p=0.000$ and business oriented with $p=0.003$. Hence, the presence of problems of health services provision in FBO's health care facilities as it was indicated in Fig.1 was due to the high running costs and business orientation notion than services provider, this make them aim at profit gain than helping the poor. In the analysis it was found out that, other independent variables do not have significant effects on health services provision in FBO's health care facilities of Dodoma urban and Kondoa districts. These are; health education to the patient $(p=0.197)$, infrastructure $(p=0.184)$, health facilities $(p=0.063)$, income of the people $(\mathrm{p}=0.745)$, ethical conducts $(\mathrm{p}=$ $0.368)$,budget in the health sector $(p=0.874)$ and working environment $(p=0.613)$. The details of all independent factors are further discussed in the below sections.

\subsubsection{Running Costs}

The presence of negative regression coefficient $(\beta=$ 0.654 ) between running costs and health services provision in FBO's health care facilities of Dodoma urban and Kondoa districts that, running costs were statistically significant $(\mathrm{p}=$ 0.000 ) affecting the magnitude of health services provision by a factor of 0.520 . Through personal communication with key informants of Safina ya Nuhu dispensary in Kondoa district, it was proved that, as running costs in FBO's health care facilities increase, the costs of health services also increase. Thus, it was difficult for FBO's to maintain quality of health service leading to absence of enough drugs, poor maintenance of the working environment and infrastructures. Therefore, an increase of running costs in FBOs health care facilities affects health services provision in FBO's healthcare facilities of Dodoma urban and Kondoa districts.

\subsubsection{Health Education of the Patients}

Though not statistically significant $(\mathrm{p}=0.197)$, poor health education of the patients affects health services provision by a factor of 1.155 as it is indicated in Table 2. Having a positive regression coefficient ( $\beta=0.144)$ implies that, 1 unit increase of health education to the patient increases the health services provision to the users and vice versa by a factor of 1.155. These results are supported by the previous study on the impacts of education and health on poverty reduction which argued that, education of the household head is vital in health decisions [14]. Furthermore, the study on sharing a legacy of caring partnership between health care and FBO's[15] argued that, disparities in health services provision are due to the lack of preventives and health education. Therefore, poor health education leads to insufficient utilization of health care facilities for patients and hence, poor health services provision in FBO's health care facilities of Dodoma urban and Kondoa districts.

\subsubsection{Infrastructure and Health Facilities}

Although not statistically significant $(p=0.184)$, infrastructure affects health services provision in FBOs health care facilities by a factor of 0.853 . Having negative regression coefficient $(\beta=-0.203)$ means that, 1 unit decrease of infrastructure decreases health services provision by a factor of 0.816 . These results complement findings by previous studies $[12,17,18]$.The studies observed that lack of infrastructure in health sectors reduces the efficiency of 
health services. Hence, the presence of poor infrastructure in Dodoma urban and Kondoa districts decreases health services provision in FBOs health care facilities.

Furthermore, Table 2shows a negative regression coefficient $(\beta=-0.203)$ of health care facilities at $p=0.063$, which implies that, a decrease in 1 unit of health care facilities decreases health services provision in FBO's health care facilities by a factor of 0.816 . These results concur with the arguments that health services provision problems in Tanzania are constrained with unbalanced between population growth and the increase of health care facilities [13]. Therefore, the presence insufficient health care facilities lead to overcrowding something which also reduces health services provision by FBO's health care facilities of Dodoma urban and Kondoa districts.

\subsubsection{Income of the Society}

Although not statistically significant $(p=0.745)$ but income to the people affects health services provision in FBO's health care facilities by a factor of 0.959 as it is indicated in Table 2. Having negative regression coefficient ( $\beta=-0.042)$ implies that, a unit decrease in income of the society decreases health services provision by a factor of 0.959. It has been argued in previous study that, income of the family is strongly associated with services utilization patterns within the community [14].Hence, low income of the people reduces access and utilization health services provision in FBO's health care facilities of Dodoma urban and Kondoa districts.

\subsubsection{Ethical Conducts for Workers}

Negative regression coefficient $(\beta=-0.101)$ between ethical conduct for workers and health services provision in FBO's health care facilities implies that, a decrease in 1 unit of ethical conduct at $p=0.368$ decreases health services provision in FBO's health care facilities by a factor of 0.904 , while an increase of 1 unit of ethical conduct for workers in FBO's health care facilities increases health services provision by a factor of 0.904 . These findings are in line with the findings of other previous studies [18, 19, 20] which identified that, abusive practices and harassment of personnel reduce efficiency of services within the community. Therefore, poor ethical conduct for workers in the health sector reduces health services provision in FBOs health care centers of Dodoma urban and Kondoa districts.

\subsubsection{Budget in the Health Sector}

Table 2 shows a negative regression coefficient $(\beta=$ 0.022 ) between budget in the health sector and health services provision in FBO's health care facilities. This implies that, decrease in 1 unit of budget in the health sector at $\mathrm{p}=0.874$ decreases health services provision in FBO's health care facilities by a factor of 0.978 and 1 unit increase of budget in the health sector increases health services provision in FBO's health care facilities by a factor of 0.978 . Other studies findings [13] support these results findings by arguing that argued that; budget determines the purchasing power in any development sector. If the budget is low, the purchasing of essential facilities is also affected. Therefore, insufficient budget in health sector reduces health services provision in FBO's health care facilities of Dodoma urban and Kondoa districts.

\subsubsection{Working Environments}

Positive regression coefficient $(\beta=0.067)$ of working environment and health services provision in FBO's health care $c$ facilities indicate that an increase of 1 unit of working environment at $\mathrm{p}=0.613$ increases health services provision in FBO's health care facilities by the factor of 1.069 , while 1 unit decrease of working environment decreases health services provision by a factor of 1.069 . Poor working environment limits providers to interact with their peers [20]. It also hinders them from continuing with medical education as well as training opportunities. Therefore, uncomfortable working environment limits health workers in FBOs health care centers to improve their professional knowledge, hence decreases health services provision in Dodoma urban and Kondoa districts.

\subsubsection{Business Oriented}

Data in Table 2 showed a positive regression coefficient ( $\beta$ $=0.286$ ) between business oriented and health services provision in FBO's health care facilities. This implies that, increase of business oriented is significantly $(p=0.003)$ increasing health services provision in FBO's health care facilities by the factor of 1.331 and vice versa. However, these results are against previous studies[5,18]who observed that increase of business in health care facilities increases costs in health services provision thus, decreases utilization of health services by the majority who are the poor. In addition, it has been contended that high costs for health services provision limits women to deliver at health care facilities, hence the remaining option was to deliver in hands of Traditional Birth Attendants (TBAs) [17]. Therefore, this reduces utilization of quality health care for the majority who are poor in Dodoma urban and Kondoa districts.

\section{Conclusions}

The study concludes that, health services provision by FBO's health care facilities in poor Tanzania can be referred to as the forgotten roles. This is due to visibility of various problems in health care facilities such as high costs for drugs, long distances from home to health care facilities, insufficient number of doctors and nurses, lack of medicines and long waiting time for treatment. The main causes of such problems being; the presence of low budget in the health sector, poor working environment, poor infrastructure, running costs and business orientation notion versus services provider as well as lack of ethical conduct for workers.

\section{Recommendations}

It is recommended that the following should be done by FBO's in order to stimulate and promote health services provision in poor Tanzania. 
i. FBO's should increase budget in the health sector to improve the status of health services provision. This would enable health care facilities to maintain essential facilities such as drugs, ambulances and laboratory equipments.

ii. Furthermore, FBO's should cooperate with the Government of Tanzania through the Ministry of Health and Social Welfare to ensure suitable skills, continuous safety, cost-effectiveness and availability of health services, through a comprehensive training for basic and continuing education to the healthy staff. Thus, curricula in health education should also be modernized to take account of the latest developments which also would insist ethics in working stations by health staff.

iii. FBO's should ensure effective management of health plans. Improvement in salaries and work conditions is a critical factor for success. Thus, there should be additional flexible career paths, supportive supervision, recognition of credit hours and continuing professional development and fostering motivation and retention strategies.

\section{References}

[1] J.Weinstein and E.Del Pozo, "Altruism and the Prospects for a Common Humanity." The Changing Face of Globalization, 2004; 98-124.

[2] R.James,"What is distinctive about FBOs? How European FBOs define and operationalise their faith." Praxis Paper 22 (2009).

[3] W.Tyndale, "Faith and economics in' development': a bridge across the chasm?." Development in practice 10.1 (2000): 918.

[4] DFID,"Faith in Development"; 2005. http://www.repository,barkleycenter,Georgetown.edu/RD20051207-BennFaith in development.pdf. Visited on $11 / 09 / 2010$

[5] A. Levin, T.Dmytraczenko, M. McEuen. F. Sengooba, R. Mangani, and G. Van Dyk,"Costs of maternal health care services in three Anglophone African countries,2003; Int J Health Plann Manage, Vol. 18, No. 1, 3-22.

[6] I.Nwachukwu, and C. Ezeh, "Impact of selected rural development programmes on poverty alleviation in Ikwuano Local Government Area, Abia State, Nigeria” ;2007. African Journal of Food, Agriculture, Nutrition and Development, Vol.7 (5) : 1-17

[7] J.Achieng,"Kenya: NGOs Seek to Import Generic Drugs from India. Geneva: Third World Network." (2001).
[8] National Bureau of Statistics(NBS), The General Report on Population Distribution by Administrative Units: 2012 PHC;2013,Dar es Salaam: National Bureau of Statistics.http://www.nbs.go.tz/.

[9] K. Wuensch,'Binary logistic regression with Statistical Package for Social Sciences",2008. [http://core.edu.edu/pspc/wuenschk/spss/spss-mv.htm], site visited on $14 / 2 / 2009$

[10] M.Nassoro, "Dodoma Regional Annual Plan 2010-201", Dodoma General Hospital. Dodoma, Tanzania; (2008).

[11] M. Mamdani, and M.Bangser, "Poor people's experiences of health services in Tanzania: A literature review, Reproductive health matters"; 2004, Vol. 12, No. 20, 138-153.

[12] S. Nsimba,A. Massele, J.Erikson, L. Gustaffson, G. Tomson, and M.Warsame, "Case management of malaria in under fives at primary health care facilities in a Tanzanian district"; 2002, Tropical medicine and International health, Vol. 7, 201209

[13] O. Olenguruma, "Challenges facing the ministry of health and social welfare in Tanzania";2012; ISSN 0850-7573, No. 04420 .

[14] R. Gounder and Z. Xing, "Impact of education and health on poverty reduction: Monetary and nonmonetary evidence from Fiji”;2012, Economic modeling, Vol. 29, No. 3, 787-794.

[15] M.Gaston, "Sharing a legacy of caring: Partnership between health care and faith based organizations"; 2001; ii-iii. Washington, DC: National Center for Cultural Competence, Georgetown University Medical Center. http://nccc.georgetown.edu/documents/ faith.pdf

[16] E. Mwaikambo,'Improving maternal, newborn and child health in Tanzania: From science to action", A presentation on Pediatrics and Child Health at Hubert Kairuki Memorial University on $5^{\text {th }}$ February, 2010.

[17] S.Matsuokaa, "Perceived barriers to utilization of maternal health services in rural Cambodia";2010;Cambodia.

[18] B. Amooti-Kaguna, and F. Nuwaha, "Factors influencing choice of delivery sites in Rakai district of Uganda"; Social Science and Medicine, 2000,Vol. 50, No. 23, 203-213.

[19] F.Grossmann-Kendall, V.Filippi,. M. De Koninck, and L.Kanhonou, "Giving birth in maternity hospitals in Benin: Testimonies of women". Reproductive Health Matters, 2001; Vol. 9, No. 18, 90-98.

[20] E. Watterberg, "Factors affecting health disparities in rural areas",2001. [www.rural.health.resources.com/speech.html], site visited on 12/08/2012. 